\title{
A Study on the Artistic Dimension of Modern Chinese Popular Music*
}

\author{
WANG Jing \\ Jinan University, Guangzhou, China
}

\begin{abstract}
Generally, criticism on popular music is of both political and artistic nature. This paper is intended to investigate modern Chinese popular music in the artistic dimension. On one hand, through analysis and differentiation in light of the two persistent (and biased) conceptions, it is necessary to acknowledge the inevitability of popular music as an art. On the other hand, this paper aims to analyze specifically the "voice” in popular music in hope of presenting its unique aesthetic characteristics. Above all, a more comprehensive view and more diverse approaches are needed in the study of popular music.
\end{abstract}

Keywords: artistic quality, aesthetic characteristics, "voice”

\section{Introduction: A Survey of Artistic Dimension}

Once labeled "obscene” and "decadent”, or even downright "poisonous seeds of capitalism”, popular music in China has reincarnated itself as a bold presence in every detail of ordinary Chinese life thanks to the needs of market economy and the power of mass media. Its new status in effect, however, didn't gain complete theoretical acknowledgement. When it comes to popular music in general, people are still inclined to frown and criticize. Granted, there are less conservative theorists defending its presence. But compared with the rampant criticism and doubt, these voices are obviously not strong or intensive enough. Most criticism and doubt arose from two concerns: politics and artistic taste. Politically, popular music is regarded by many, Frankfurt School (or Critical School) in particular, as an ideological tool for the ruling class of capitalist society to manipulate the masses. In terms of artistic taste, it is the spoken or written opinion, which seems almost "intuitive", of many an artist and critic deeply cultivated in sophisticated music and art, that sees popular music and in fact the entirety of popular culture products as deficient in true artistic qualities, or quiet plainly, of low taste. Of the latter, Adorno's critical work, On Popular Music, is a highly acclaimed culmination. While they may be politically and artistically challenged, popular music and its related art forms in China today which remain more or less "spontaneous", have both seriously cultural functions and significantly political implications. For lack of more length, the

\footnotetext{
* Acknowledgement: This paper is the partial result of the research project "Study on the Influence of Modern Popular Music on the Affective Identification of Young People”, a Ministry of Education Youth Project of Humanities and Social Sciences (No. 12YJCZH317).

For the author's lack of English proficiency in reading, all of the citations in this paper are from the Chinese translations of the original English works.

WANG Jing, female, Doctor of Literature, Lecturer of College of Chinese Language and Culture, Jinan University, Guangzhou, specializing in research on 20C Chinese literature and culture and Teaching Chinese as Foreign Language.
} 
purpose of this paper is to examine and measure popular music in the artistic dimension.

\section{The Inevitability of Popular Music as an Art}

Any attempt to artistically justify popular music is often confronted with two challenges:

First, the guard against and refusal of popular music as commercialized and pursuant to economic gains, which arose at the beginning of the infantry of modern aesthetics and have taken root in the general mindset. Whether it is the Kantian argument that our judgments of artistic beauty must be "disinterested", or Critical School's revelation of "alienation" in the modern society and their idea of "redemption" through art, they are in fact theoretical expressions of the guard and refusal. In both contexts, what is legitimately established as "art" must be free of earthly desires and cut off from everyday events and clashes of material interests. Anything other than this will not be identified as "art" and is very likely to be accused of being the tool of "alienation".

Is it true, we must ask, that the acknowledged "works of art" are really insulated from everyday events and practical interests? With a social and historical approach, John Dewey revealed the profound political and economic implications of art under the appearance of separation from everyday life and “disinterested" judgments:

...Most European museums are, among other things, memorials of the rise of nationalism and imperialism. Every capital must have its own museum of paintings, sculpture, etc., devoted in part to exhibiting the greatness of its artistic past, and, in other part, to exhibiting the loot gathered by its monarchs in conquest of other nations; for instance, the accumulations of the spoils of Napoleon that are in the Louvre. They testify to the connection between the modern segregation of art and nationalism and militarism....

...Generally speaking, the typical collector is the typical capitalist. For evidence of good standing in the realm of higher culture, he amasses paintings, statuary, and artistic bijoux, as his stocks and bonds certify to his standing in the economic world. "Modern industry and commerce have an international scope. The contents of galleries and museums testify to the growth of economic cosmopolitanism....As works of art have lost their indigenous status, they have acquired a new one ...that of being specimens of fine art and nothing else. Moreover, works of art are now produced, like other articles, for sale in the market. (Dewey, 2010, pp. 9-10)

What Dewey eloquently argued proves that it is only a matter of willful theoretical "imagination" to suggest the insulation of art from practical interests. If the artistic products enshrined in museums and galleries are in fact "produced for sale in market", on what ground do we reject popular music of its title of "art"? True, certain level of alarm is needed, when business interests become the top or the only concern of music to the point of "alienation", but as the term suggests, being alienated means a distortion of one's true will. In other words, alienation in itself suggests one's very own true will, without which there would be nothing to distort. JIN Zhaojun, a Chinese scholar of popular music, gave an interesting example. During the time of rejuvenation of popular music industry in Mainland China, a business-owner in the industry bluntly expressed his aspiration, "What I am expecting to hear in the records is the sound of cash!" Obviously, a record with tracks of sounds of notes and coins cannot bring actual cash. It is the music and singing that does the trick. In a society where commercialization is the basic form of exchange, music is merely a means to the end of doing business. But one cannot reach the end without the means, for the need of purchase is created by the need for music. It is in the very nature of commercialization to pursue business interests by meeting the consumers' needs. By this rationale, the secret to avoid alienation lies both in music creators' persistence to their aesthetic goals, and in the elevation of the appreciative facility of the receiving subjects. Once this decisive factor plays out, 
commercial goals must give way to aesthetic ones. Therefore, popular music should not be rejected on the ground of commercialization and pursuit of business interests. It is more valuable, rather, for us to investigate the reasons why popular music (and other popular art forms) is commercialized as it is.

The second challenge facing popular music is the question of its artistic level. Measured by the standards of classical music, popular music is crude and simple, if not downright low and base. To respond to the question, we must go back to aesthetics itself to seek how popular music is beautiful in its own way different from classic art.

To the exhaustion of the author's literary scope, the most powerful aesthetic argument on this issue comes from Shusterman, who came crushing with his proposal of "Somaesthetics" to discover the unique aesthetic qualities of popular music and defend its aesthetic legitimacy.

In his defense strategy, Shusterman approaches this issue with two arguments. On one hand, in the light of analytical philosophy, he points out the logical fallacies of various critical aesthetic accusations against popular art. A good example is the well-known opinion that popular art cannot provide true aesthetic satisfaction, which is based on two claims: first, popular art only offers transient satisfaction; second, it only offers substitutional satisfaction instead of the "more basic and genuine pleasure". Both claims are logically unsound because: one, what is transient is not necessarily false; two, the "more basic and genuine pleasure" does not exist in the real world as much as it does in a transcendental world. Many similar opinions that deny the aesthetic legitimacy of popular art indeed are not tenable. On the other hand, starting from the ground of pragmatic aesthetics, Shusterman unveiled the distinctive beauty of popular art different from that of classic art. According to him, there is a common "anti-body" aesthetic conception expressed in the collective criticism of popular art, which is an inherent part of classic art. However, what popular art emphasizes is none other than what the body feels and practices. Of all the forms of popular art, Shusterman focused on popular music.

In his widely accredited work, Pragmatic Aesthetics: Living Beauty, Rethinking Art, Shusterman studied such popular music genres as Jazz, Rock and Rap. In his words:

The more robust and muscular kinesthetic response stimulated by Rock music reveals the ultimate passiveness of the disinterested and distant traditional aesthetic attitude-a meditative attitude, which comes from the pursuit of philosophical and theological knowledge rather than pleasure, of personal enlightenment rather than mutual influence of the public or social reforms. Popular art such as Rock music demonstrates the fundamental and revised aesthetics by returning to pleasure in the physical realm. (Shusterman, 2002, pp. 244-245)

Calling himself a rap fan, Shusterman then did an analytical study of some of the most representative rap songs. His conclusion was that the DJ samples and synthesis together create a special musical effect which "challenges the notions of originality and uniqueness that has been binding our artistic concepts" (Shusterman, 2002, p. 245). Moreover in the rap songs, the semantic ambiguity and complexity of African American slangs, the complicated attitude towards mass communication and commercialization, etc. All meet the standards of conventions as well as challenge them which are critical to aesthetic legitimacy. As a result, what is generated was a typical post-modernist aesthetic practice, in which the realm of body was greatly displayed:

They require the ultimate appreciation by dancing energetically and passionately, in stead of by still contemplation and dispassionate study...This divine and physically frantic aesthetics ... may remind us of Vodun and African metaphysics, to which African American music can be aesthetically traced back. (Shusterman, 2002, p. 284) 
There are profound philosophical and aesthetic motives behind Shusterman's advocacy of "somaesthetics" or physical nature of aesthetics. In other words, it reflects a refutation of the oppression and contempt against "body" which is long-lasting in western philosophy and aesthetics. "Body" is an issue too complicated and significant to elaborate in this paper. Admittedly, whether the contentions of somaesthetics apply perfectly to Chinese popular music and other art forms is still open for debate, given, for instance, the innate distinction between Chinese traditional conception of "body" and that of the western philosophy which features the dichotomy of flesh and soul, it is not entirely groundless, however, to adopt a somaesthetic perspective to shed some light on them, for the transformation of Chinese society has provided many channels for the west to meet the east in terms of ideas, culture and social life.

One thing we can learn from Shusterman's study, among others, is that popular art has its own aesthetic qualities different from those of classic art. It is by its own aesthetic standards that popular art is to be judged and any mechanic application of the principles of classic art would simply lead to misinterpretation or oppression. Having said this, popular art needs to establish its own aesthetic pursuit to improve and perfect itself, rather than follow blindly and exclusively the market. As Shusterman illustrated in his proposal of a "middle ground":

My idea of the middle ground is one that embraces reformism, which admits the severe weaknesses and harms of popular art while acknowledging its merits and potential. It advocates that popular art should be reformed, for there are plenty to be improved, and that it can be reformed, for it frequently attains true aesthetic merits and serve valuable social purposes. It insists that popular art should gain serious aesthetic attention, since expulsion of it as something below aesthetic concern means none other than to leave its judgment and its future to the mercy of the most profit-oriented market. The long-term goal of the reformists, so to speak, is to steer an investigation free from general accusation or admiration, so that attention can be better focused on more specific issues and detailed improvements. (Shusterman, 2002, p. 235)

To pay "serious aesthetic attention" to popular art, or to examine popular art as true subjects of art, does not necessarily entail that the beauty of popular art is simply the display of "somaesthetics" or beauty in the physical realm, but it seems aesthetically inevitable now to seek and investigate the distinctive aesthetic qualities of popular art, e.g. popular music.

\section{The "Voice": A Key Aesthetic Feature of Popular Music}

So what are the aesthetic characteristics of popular music? For the sake of commercial needs as well as the reliance on technologies of mass media, popular music appears to be, more than others, heavily synthetic, composed of singing, lyrics, music score, instrumental performance and music producing (e.g. processing, music video and image design). These five elements decide the success of popular music work. In other words, they all function significantly in their artistic qualities. It is exactly this high level of composition, however, that resulted in the general impression that the non-musical factors (such as music producing) outweigh the musical ones, while the truth is a more complex "musical image" which is generated by none other than the combination of non-musical and musical factors. If classic music acquires its image by means of sound symbols (of the singer and musical instruments), then the image of popular music must be presented with the image of the singer, as well as the visual symbols concerning the implications of the music. For popular music, it is the synthetic music image that is presented to its receivers. True, sauce at times tastes better than the fish in 
the construction of music image, but generally what satisfies the popular music lovers is still essentially musical. This author's research shows that any one or more of the three factors, singing, lyrics and music score, attract significantly larger audiences of popular music than the others. While the research does not indicate any substantial preference among the three, it is the opinion of the author that singing, or the voice of the singer best manifests the aesthetic characteristics of popular music in terms of aesthetic differences.

In Roland Barthes's terms, "the voice" is not about the music, chorus or lyrics, but a unique quality of the voice. Besides, musical instruments only serve a complementary purpose as far as singing art is concerned, which makes the voice all the more important. When it comes to the art of popular music, certain phrasal and rhythmical patterns generated have indeed become classic. Yet compared with classic music, it still remains generally simplistic in terms of the lyrics and music. While this may be true, if a comparison is made in terms of cultivation and utilization of "the voice", however, popular music is not inferior, if not equal, to classic music.

There are two generally accepted styles of singing in China, namely, bel canto and folk style. Each forms its own distinctive system of vocalization. A special feature of bel canto is the columnar resonance of the three cavities-head, mouth and chest, which prioritizes continuance, smoothness and fluency, at times even at the cost of inaccurate pronunciation of certain sounds. With folk singing, performers try to vocalize through the back of cranial cavity and to be accurate in articulation. While they may differ from each other in ways of vocalization, in both ways musical sounds are what we hear, the kind of sounds that are produced by regular, periodical vibration at their source. Comparatively speaking, larynx is the most common organ of vocalization for popular music, leading many to believing that the sounds are shallow and unprofessional. As a matter of fact, it is this unique way of vocalization that gives popular music its unusual charm.

In Saussure's distinction of "signified" and "signifier", there needs to be no logical connection between the two. Instead, the connection is random. "Signifier" refers to "image acoustique" or "sound image" produced by vocal organs, while "signified" refers to the "concept" corresponding to the "sound image". A sign is then compared to a coin with two sides. In terms of Chinese language, if the signifier is the combination of the initial consonant, the simple or compound vowel, and the intonation of a Chinese syllable, the signified would be the meaning of the Chinese character. Given the expressive function achieved by difference of volume and/or speed in actual word flow, it is fairly obvious that the issue of "timbre", even on the level of syllables, is elusive from Saussurean semiology. In the context of acoustic aesthetics, however, timbre is an essential issue not to be neglected, for it generates the aesthetic feeling of a sound. It is safe to say that the dualistic theory of signs does not apply very well to the actuality of sound, and is in fact likely to hinder the aesthetic study of sound or singing.

The truth is that timbre is critical in the practice of the art of sound. In a sense, all kinds of singing training serve the one purpose - to give full play to the special qualities of the timbre. Aesthetic standards vary, of course, in different types of singing. Generally speaking, with classic music people expect the singers to be, among others, sonorous, smooth and full (which obviously are more felt than measured), whereas a singer of popular music tends to explore different vocal organs to their unique effects, to include more irregular overtones, in hope of creating his/her own special sound quality. 
This quality is often referred to in popular music reviews as the vocal "recognizability" of a certain performer, through which a distinctively individualized sound space is presented to the audience, leaving them the instant impression that this is something different from the others. The voice, therefore, is the most captivating musical element in the performance of popular music. A popular singer's "recognizability", then, would be decisive of his/her success. Different from folk style or bel canto, which usually emphasizes the smoothness and fullness of the voice, popular music is more diverse, subject to variation, allowing or even encouraging irregular vocalization, to the point of admitting non-musical sounds. Take "yan sang” (literally "smoked voice") for example, an unprofessional term describing the coarse voice of a singer which sounds as if it'd been smoked. While unaccepted in classic music or art song singing, the "smoked voice", as coarse as it is, suits some listeners for its unique magnetic quality is expressive of a sense of vicissitudes and dispiritedness, which gives an unexpected appeal. Chinese rock singer, CUI Jian, with his "roar-like" singing and stars like LUO Dayou and WU Bai with their "trembling" voices, are all considered irregular vocalization, but their uniqueness can never be forgotten. It is this author's belief that the emphasis on vocal "recognizability" in popular music brings our concern directly to the non-ideographic level of sound. We must, at this point, get past the Saussurean conception of signs and perceive sound as a non-closed and non-planarized texture, to do justice to the non-ideographic irregular overtones in the aesthetic study of singing.

It is understandable to accuse popular singing as unscientific, for it frequently involves overuse or incorrect use of certain vocal parts, leaving the singer to "dao sang” (lose one's voice), as manifested by the fact that some rock and pop stars had to end their careers before reaching 40 . But on the bright side, the characteristic singing styles present the unique vocal qualities of these singers to the full extent, without which the singers can never express the significance of a song, nor listeners be rewarded with an ecstatic experience. (Should a listener find extreme pleasure listening to the singer creating his/her unique sound by special way of friction of vocal organs, he/she may even experience involuntary shuddering, a feeling that young people called “dai jin" in the 80s, or "ku” in the 90s, or "diao" today, all meaning "cool” or "awesome”, which is certainly different from the general response to classic music or art). For this reason, popular singers tend to make relentless efforts to explore their own unique sound qualities, knowing fully well the risk they are taking (as proved by the legends and stories recorded in JIN Zhao Jun's book, Popular in Broad Daylight: Chinese Popular Music).

So it is safe to say that cultivation and utilization of the special qualities of the voice put the art of popular music in a unique aesthetic position distinctively different from that of the classic music. In the very first place, through the voice lyricism of popular music is firmly rooted in the authenticity of "body". Musically, Chinese ancient wisdom has this to say: "si bu ru zhu, zhu bu ru rou", meaning that stringed music is outvalued by wind music, which is then outvalued by vocal singing. Evident of our ancestors' aesthetic preference of nature, this also speaks sufficiently of the superiority of a singer's voice to a musical instrument. It is true that the latter can produce sound that many of us humans fail to, e.g. higher pitch or greater volume, given the fact that human voice is constrained by its natural limitations. But if we define the purpose of music as emotional expression, then the advantage of human voice is obvious - it expresses emotions more directly and exquisitely. However fine the musical instrument is, it is only an imitation of human emotion, but our emotions are already incorporated in our voices. Speaking in this context, popular music is even one step more advanced than classic 
music artistically. As is stated, its acceptance of more irregular vocal performance in effect broadens the scope of emotional expression through sound. It does not exclude "musical sounds", nor is exclusively pursuant to them. Instead, it pushes the natural quality of the singer's voice to an extreme, to the effect of bringing the unexpected aesthetic satisfaction to the listeners and stimulating a physical ecstasy in them. In the second place, by de-typifying the voice, the popular music industry is then de-typified. Artistically, popular music actively embraces experiments of irregular musical compositions that are deviant from classic music art, spawning various music genres. While commercial needs do give rise to a number of copycats following the suit of certain musical type of fad, which in turn results in typification in the popular music industry, the pursuit of uniqueness and recognizability of "the voice" has never been put to rest. Once in a talent show, one of the young contestants did an uncanny impression of the popular star, XU Wei, only to be rejected by the judge, CAI Guoqing, also a well-known popular singer. CAI's reason was simple: only one XU Wei is needed in the popular music arena. When we consider the thousand similar voices indiscriminatingly singing the same one folk song a few years back, it almost seems too harsh how particular popular music is about the "recognizability" of the voice. The realities of popular music provide sufficient proof: the overwhelming majority of the top popular musicians, most of the luminous stars, have their uniquely different voices to offer. It is unfair, therefore, to deny the de-typifying endeavor of popular music through vocal performance, just because as an industry, it is typically produced.

\section{Conclusion}

Vocal performance is, of course, not the only manifestation of the different aesthetics of popular music. There are other musical elements as well. As Bernard Gendron proposes on the differences between classical and popular music, "The western classical music is concentrated on the melodies and chords, whereas modern popular music is concerned with sound quality and the meaning or implications, changes in which (as in the rise of Rock and Roll) are considered more revolutionary than in the technique of chords” (Gendron, 2001, p. 225). Moreover, classic music impresses us as precise and prudential, conforming to regularity, either in terms of a basic musical sound or the whole composition. Popular music, however, often appears to be deviant from this regularity, presenting inharmonious yet uniquely meaningful music images. A guitarist may use the effecter to alter the timbre of the guitar to produce a sound that is somewhere between a musical sound and pure noise. Or sometimes he/she would just go wild on the guitar. A drummer, on the other hand, may place a bunch of keys on the cymbals to add a little coarse feel. Jazz trumpeters and trombonists sometimes play in a "roaring" style. Structurally, popular music is also distinctively different from classical music. An example is the Blues music, which cannot be categorized as "major" or "minor" according to classical music system. The unique style of Blues makes it even hard to be recorded in musical notes. All these structural irregularities of popular music are not easy for audience of classical music to adopt. The author would cite another example, "sheng ru xia hua”, or Life Like Summer Flowers, by popular singer PIAO Shu, which may sound most bizarre to people with an ear for classical music. For whenever they feel the music should go up, it goes down. Even though this may fail their aesthetic expectation, it makes the popular music fans feel unexpectedly comfortable.

Young Chinese receive popular music based on their complex needs, including their looming political appeal, wrapped in the criticism, rebellion and subversion of the once popular Rock scene and the on-going 
Rap scene. However, it goes without saying that their reception of popular music, first and foremost, is based on their aesthetic satisfaction. To foreground the artistic dimension of popular music, therefore, is not only doing justice to its reception. More importantly, it affords us a more comprehensive view and provides us with more diversified approaches out of the ideological tradition of analysis to the research and study of popular music.

\section{References}

Dewey, J. (2010). Art as experience (J. P. GAO, Trans.) (pp. 9-10). Beijing: Commercial Press.

Fiske, J. (2001). Understanding popular culture (X. J. WANG, Trans) (p. 53). Beijing: Central Compliation \& Translation Press.

Gendron, B. (2001). Theodor adorno meets the cadillacs. In Y. LU and Y. WANG, Studies of popular culture. Shanghai: Shanghai Joint Publishing Press.

JIN, Z. J. (2002). Popular in broad daylight: Chinese popular music. Beijing: People’s Music Publishing House.

Shusterman, R. (2002). Pragmatic aesthetics: Living beauty, rethinking art (F. PENG, Trans.). Beijing: Commercial Press. 